\title{
Bag Telephone Data Type
}

National Cancer Institute

\section{Source}

National Cancer Institute. Bag Telephone Data Type. NCI Thesaurus. Code C95629.

A data type comprised of an unordered collection of telephone numbers. 